\title{
Controlled Growth of C-Oriented AIN Thin Films: Experimental Deposition and Characterization
}

\author{
Manuel García-Méndez \\ Centro de Investigación en Ciencias Físico-Matemáticas, \\ FCFM de la UANL Manuel L. Barragán S/N, Cd. Universitaria,
}

México

\section{Introduction}

Nowadays, the science of thin films has experienced an important development and specialization. Basic research in this field involves a controlled film deposition followed by characterization at atomic level. Experimental and theoretical understanding of thin film processes have contributed to the development of relevant technological fields such as microelectronics, catalysis and corrosion.

The combination of materials properties has made it possible to process thin films for a variety of applications in the field of semiconductors. Inside that field, the nitrides III-IV semiconductor family has gained a great deal of interest because of their promising applications in several technology-related issues such as photonics, wear-resistant coatings, thin-film resistors and other functional applications (Moreira et al., 2011; Morkoç, 2008).

Aluminium nitride $(A l N)$ is an III- $V$ compound. Its more stable crystalline structure is the hexagonal würzite lattice (see figure 1). Hexagonal AlN has a high thermal conductivity (260 Wm-1 $\left.\mathrm{K}^{-1}\right)$, a direct band gap $\left(\mathrm{E}_{\mathrm{g}}=5.9-6.2 \mathrm{eV}\right)$, high hardness $\left(2 \times 10^{3} \mathrm{kgf} \mathrm{mm}^{-2}\right)$, high fusion temperature $\left(2400^{\circ} \mathrm{C}\right)$ and a high acoustic velocity. AlN thin films can be used as gate dielectric for ultra large integrated devices (ULSI), or in GHz-band surface acoustic wave devices due to its strong piezoelectricity (Chaudhuri et al., 2007; Chiu et al., 2007; Jang et al., 2006; Kar et al., 2006; Olivares et al., 2007; Prinz et al., 2006). The performance of the AlN films as dielectric or acoustical/electronic material directly depends on their properties at microstructure (grain size, interface) and surface morphology (roughness). Thin films of AlN grown at a c-axis orientation (preferential growth perpendicular to the substrate) are the most interesting ones for applications, since they exhibit properties similar to monocrystalline AlN. A high degree of $c$-axis orientation together with surface smoothness are essential requierements for $A l N$ films to be used for applications in surface acoustic wave devices (Jose et al., 2010; Moreira et al., 2011).

On the other hand, the oxynitrides $\mathrm{MeN}_{\mathrm{x}} \mathrm{O}_{\mathrm{y}}$ (Me=metal) have become very important materials for several technological applications. Among them, aluminium oxynitrides may have promissing applications in diferent technological fields. The addition of oxygen into a growing $A l N$ thin film induces the production of ionic metal-oxygen bonds inside a matrix 
of covalent metal-nitrogen bond. Placing oxygen atoms inside the würzite structure of AlN can produce important modifications in their electrical and optical properties of the films, and thereby changes in their thermal conductivity and piezoelectricity features are produced too (Brien \& Pigeat, 2008; Jang et al., 2008). Thus, the addition of oxygen would allow to tailor the properties of the $\mathrm{AlN}_{\mathrm{x}} \mathrm{O}_{\mathrm{y}}$ films between those of pure aluminium oxide $\left(\mathrm{Al}_{2} \mathrm{O}_{3}\right)$ and nitride (AIN), where the concentration of $\mathrm{Al}, \mathrm{N}$ and $\mathrm{O}$ can be varied depending on the specific application being pursued (Borges et al., 2010; Brien \& Pigeat, 2008; Ianno et al., 2002; Jang et al., 2008). Combining some of their advantages by varying the concentration of $A l, N$ and $O$, aluminium oxynitride films (AlNO) can produce applications in corrosion protective coatings, optical coatings, microelectronics and other technological fields (Borges et al., 2010; Erlat et al., 2001; Xiao \& Jiang, 2004). Thus, the study of deposition and growth of AlN films with the addition of oxygen is a relevant subject of scientific and technological current interest.

Thin films of AlN (pure and oxidized) can be prepared by several techniques: chemical vapor deposition (CVD) (Uchida et al., 2006; Sato el at., 2007; Takahashi et al., 2006), molecular beam epitaxy (MBE) (Brown et al., 2002; Iwata et al., 2007), ion beam assisted deposition (Lal et al., 2003; Matsumoto \& Kiuchi, 2006) or direct current (DC) reactive magnetron sputtering.

Among them, reactive magnetron sputtering is a technique that enables the growth of $c$-axis AlN films on large area substrates at a low temperature (as low as $200^{\circ} \mathrm{C}$ or even at room temperature). Deposition of AlN films at low temperature is a "must", since a high-substrate temperature during film growth is not compatible with the processing steps of device fabrication. Thus, reactive sputtering is an inexpensive technique with simple instrumentation that requires low processing temperature and allows fine tuning on film properties (Moreira et al., 2011).

In a reactive $D C$ magnetron process, molecules of a reactive gas combine with the sputtered atoms from a metal target to form a compound thin film on a substrate. Reactive magnetron sputtering is an important method used to prepare ceramic semiconducting thin films. The final properties of the films depend on the deposition conditions (experimental parameters) such as substrate temperature, working pressure, flow rate of each reactive gas $\left(\mathrm{Ar}, \mathrm{O}_{2}, \mathrm{~N}_{2}\right)$, power source delivery (voltage input), substrate-target distance and incidence angle of sputtered particles (Ohring, 2002). Reactive sputtering can successfully be employed to produce $A l N$ thin films of good quality, but to achieve this goal requires controlling the experimental parameters while the deposition process takes place.

In this chapter, we present the procedure employed to grow AlN and AlNO thin-films by $D C$ reactive magnetron sputtering. Experimental conditions were controlled to get the growth of c-axis oriented films.

The growth and characterization of the films was mainly explored by way of a series of examples collected from the author's laboratory, together with a general reviewing of what already has been done. For a more detailed treatment of several aspects, references to highly-respected textbooks and subject-specific articles are included.

One of the most important properties of any given thin film system relies on its crystalline structure. The structural features of a film are used to explain the overall film properties, which ultimately leads to the development of a specific coating system with a set of required properties. Therefore, analysis of films will be concerned mainly with structural characterization. 
Crystallographic orientation, lattice parameters, thickness and film quality were characterized through X-ray Diffraction (XRD) and UV-Visible spectroscopy (UV-Vis). Chemical indentification of phases and elemental concentration were characterized through X-ray photoelectron spectroscopy (XPS). From these results, an analysis of the interaction of oxygen into the AlN film is described. For a better understanding of this process, theoretical calculations of Density of States (DOS) are included too.

The aim of this chapter is to provide from our experience a step wise scientific/technical guide to the reader interested in delving into the fascinating subject of thin film processing.

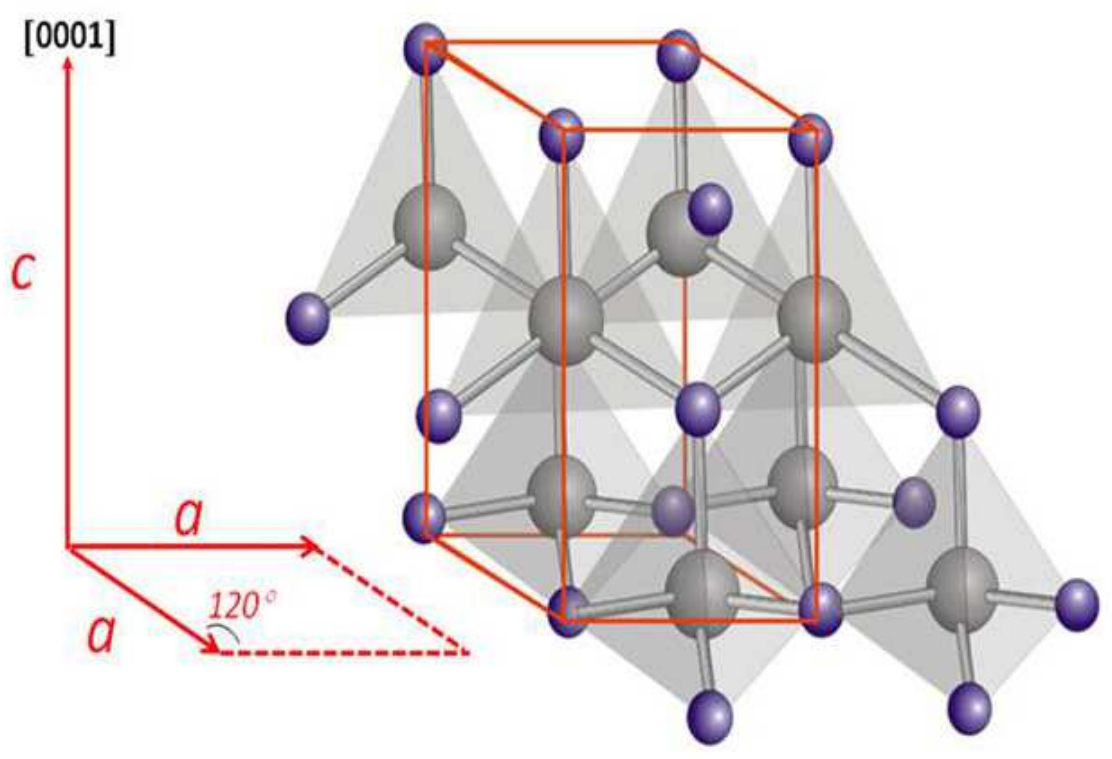

Fig. 1. Würzite structure of AlN. Hexagonal AlN belongs to the space group $6 \mathrm{~mm}$ with lattice parameters $\mathrm{c}=4.97 \AA$ and $\mathrm{a}=3.11 \AA$.

\section{Deposition and growth of AIN films}

The sputtering process consists in the production of ions within generated plasma, on which the ions are accelerated and directed to a target. Then, ions strike the target and material is ejected or sputtered to be deposited in the vicinity of a substrate. The plasma generation and sputtering process must be performed in a closed chamber environment, which must be maintained in vacuum. To generate the plasma gas particles (usually argon) are fed into the chamber. In DC sputtering, a negative potential $U$ is applied to the target (cathode). At critical applied voltage, the initially insulating gas turns to electrical conducting medium. Then, the positively charged $\mathrm{Ar}^{+}$ions are accelerated toward the cathode. During ionization, the cascade reaction goes as follows: 


$$
\mathrm{e}^{-}+\mathrm{Ar} \rightarrow 2 \mathrm{e}^{-}+\mathrm{Ar}^{+}
$$

where the two additional (secondary) electrons strike two more neutral ions that cause the further gas ionization. The gas pressure " $\mathrm{P}$ " and the electrode distance " $\mathrm{d}$ " determine the breakdown voltage " $\mathrm{V}_{\mathrm{B}}$ " to set the cascade reaction, which is expressed in terms of a product of pressure and inter electrode spacing:

$$
V_{B}=\frac{A P d}{\ln (P d)+B}
$$

where A and B are constants. This result is known as Paschen's Law (Ohring, 2002).

In order to increase the ionization rate by emitted secondary electrons, a ring magnet (magnetron) below the target can be used. Hence, the electrons are trapped and circulate over the surface target, depicting a cycloid. Thus, the higher sputter yield takes place on the target area below this region. An erosion zone (trace) is "carved" on the target surface with the shape of the magnetic field.

Equipment description: Films under investigation were obtained by $D C$ reactive magnetron sputtering in a laboratory deposition system. The high vacuum system is composed of a pirex chamber connected to a mechanic and turbomolecular pump. Inside the chamber the magnetron is placed and connected to a DC external power supply. In front of the magnetron stands the substrate holder with a heater and thermocouple integrated. The distance target-substrate is about $5 \mathrm{~cm}$ and target diameter 1 ". The power supply allows to control the voltage input (Volts) and an external panel display readings of current (Amperes) and sputtering power (Watts) (see Figure 2).
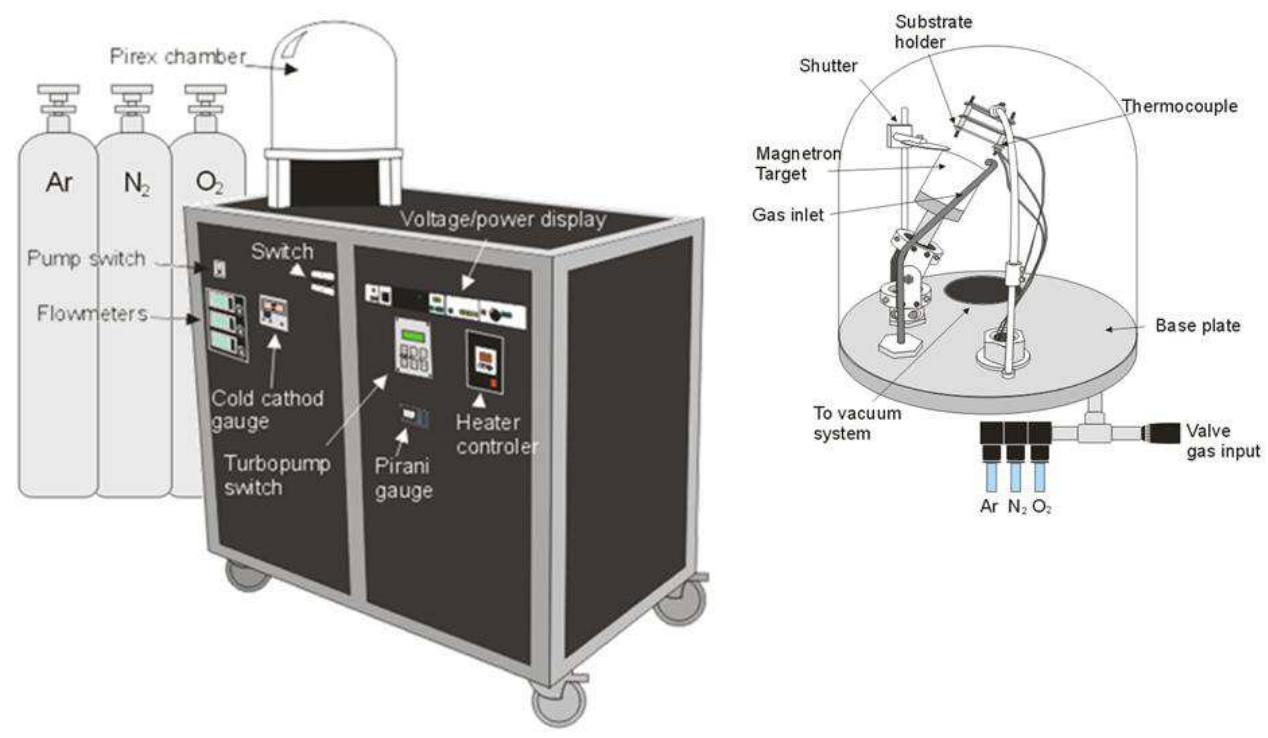

Fig. 2. Schematic diagram of the equipment utilized for film fabrication. 
Deposition procedure: A disc of $A l$ (2.54 cm diameter, $0.317 \mathrm{~cm}$ thick, $99.99 \%$ purity) was used as a target. Films were deposited on silica and glass substrates that were ultrasonically cleaned in an acetone bath. For deposition, the sputtering chamber was pumped down to a base pressure below $1 \times 10^{-5}$ Torr. When the chamber reached the operative base pressure, the Al target was cleaned in situ with $\mathrm{Ar}^{+}$ion bombardment for 20 minutes at a working pressure of $10 \mathrm{mTorr}(20 \mathrm{sccm}$ gas flow). A shutter is placed between the target and the substrate throughout the cleaning process. The Target was systematically cleaned to remove any contamination before each deposition.

Sputtering discharge gases of $\mathrm{Ar}, \mathrm{N}_{2}$ and $\mathrm{O}_{2}$ (99.99\% purity) were admitted separately and regulated by individual mass flow controllers. A constant gas mixture of $A r$ and $N_{2}$ was used in the sputtering discharge to grow AlN films; a gas mixture of $A r, N_{2}$ and $\mathrm{O}_{2}$ was used to grow AlNO films.

A set of eight films were prepared: four samples on glass substrates (set 1) and four samples on silica substrates (set 2). From set 1, two samples correspond to AlN (15 min of deposition time, labeled S1 and S2) and two to AlNO (10 min of deposition time, labeled S3 and S4). From set 2, three samples correspond to AlN (10 min of deposition time, labeled S5, S6 and S7) and one to AlNO (10 min of deposition time, labeled S8). All samples were deposited using an $\mathrm{Ar}$ flow of $20 \mathrm{sccm}$, an $\mathrm{N}_{2}$ flow of $1 \mathrm{sccm}$ and an $\mathrm{O}_{2}$ flow of $1 \mathrm{sccm}$. In all samples (excluding the ones grown at room temperature.), the temperature was supplied during film deposition.

Tables 1 (a) (set 1) and 1 (b) (set 2) summarize the experimental conditions of deposition. Calculated optical thickness by formula 4 is included in the far right column.

\begin{tabular}{|c|c|c|c|c|}
\hline Sample & $\left(\right.$ Film) ${ }^{\circ} \mathrm{C}$-time & V (Volts) & $P$ (Watts) & $\begin{array}{c}\text { Thickness } \\
\text { (nm) }\end{array}$ \\
\hline S1 & $(A l N)$ RT-15 min & 360 & 120 & 980 \\
\hline$S 2$ & $(A I N) 100^{\circ} \mathrm{C}-15 \mathrm{~min}$ & 360 & 130 & 970 \\
\hline$S 3$ & $(A l N O)$ RT-10 min & 360 & 190 & 820 \\
\hline S4 & $($ AlNO $) 120^{\circ} \mathrm{C}-10 \mathrm{~min}$ & 360 & 185 & 940 \\
\hline
\end{tabular}

Table 1a. Deposition parameters for DC sputtered films grown on glass substrates (set 1)

\begin{tabular}{c|cccc}
\hline Sample & (Film) $^{\circ}$ C - time & V (Volts) & P (Watts) & $\begin{array}{c}\text { Thickness } \\
(\text { nm })\end{array}$ \\
\hline S5 & $($ AlN $) \mathrm{RT}-10 \mathrm{~min}$ & 340 & 100 & 630 \\
S6 & $\left(\right.$ AlN $100^{\circ} \mathrm{C}-10 \mathrm{~min}$ & 330 & 110 & 630 \\
S7 & $($ AlN $) 200^{\circ} \mathrm{C}-10 \mathrm{~min}$ & 340 & 120 & 730 \\
S8 & $($ AlNO $\mathrm{RT}-10 \mathrm{~min}$ & 380 & 140 & 490 \\
\hline
\end{tabular}

Table 1b. Deposition parameters for DC sputtered films grown on silica substrates (set 2). 


\section{Structural characterization}

XRD measurements were obtained using a Philips X'Pert diffractometter equipped with a copper anode $K \alpha$ radiation, $\lambda=1.54 \AA$. High resolution theta/2Theta scans (Bragg-Brentano geometry) were taken at a step size of $0.005^{\circ}$. Transmission spectra were obtained with a UV- Visible double beam Perkin Elmer 350 spectrophotometer.

Figure 3 (a) and (b) display the XRD patterns of the films deposited on glass (set 1) and silica (set 2) substrates, respectively.

The diffraction pattern of films displayed in figure 3 match with the standard AlN würzite spectrum (JCPDS card 00-025-1133, a=3.11 $\AA$, c=4.97 $\AA$ ) (Powder Diffraction file, 1998). The highest intensity of the (002) reflection at $2 \theta \approx 35.9^{0}$ indicates an oriented growth along the $c$ axis perpendicular to substrate.

From set 1, it can be observed that the intensity of (002) diffraction peak is the highest in S2. In this case, the temperature of $100^{\circ} \mathrm{C}$ increased the crystalline ordering of film. In S3 and $S 4$ the intensity of (002) diffraction and grain size are very similar for both samples, which shows that applied temperature on $S 4$ had not effect in improving its crystal ordering.

From set 2, it can be observed that the intensity of (002) diffraction peak is the highest in S5. Generally, temperature gives atoms an extra mobility, allowing them to reach the lowest thermodynamically favored lattice positions hence, the crystal size becomes larger and the crystallinity of the film improves. However, the temperature applied to $S 6$ and $S$ s makes no effect to improve their crystallinity. In this case, a substrate temperature higher than $100^{\circ} \mathrm{C}$ can trigger a re-sputtering of the atoms that arrive at the substrate's surface level and crystallinity of films experiences a downturn.

From set 1 and set 2, S2 and S5, respectively, were the ones that presented the best crystalline properties. A temperature ranging from RT to $100^{\circ} \mathrm{C}$ turned out to be the critical experimental factor to get a highly oriented crystalline growth.
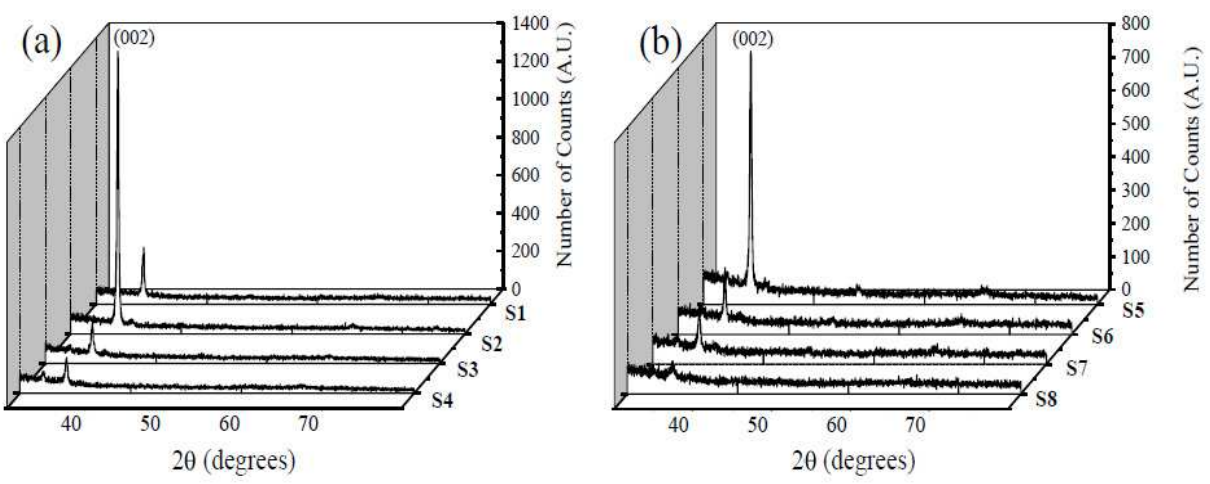

Fig. 3. XRD patterns of films deposited on (a) glass and (b) silica substrates.

In terms of the role of oxygen, for $S 3, S 4$ and $S 8$, the presence of alumina $\left(\gamma-\mathrm{Al}_{2} \mathrm{O}_{3}\right.$ : JCPDS file 29-63) or spinel ( $\gamma$-AlON: JCPDS files 10-425 and 18-52) compounds in the diffraction patterns 
was not detected. However, it is known from thermodynamic that elemental aluminium reacts more favorably with oxygen than nitrogen: it is more possible to form $\mathrm{Al}_{2} \mathrm{O}_{3}$ by gaseous phase reaction of $A l+(3 / 2) O_{2}$ than $A l N$ of $A l+(1 / 2) N$ since $\Delta G\left(\mathrm{Al}_{2} \mathrm{O}_{3}\right)=-1480 \mathrm{KJ} / \mathrm{mol}$ and $\Delta G(A l N)=-253 \mathrm{KJ} / \mathrm{mol}$ (Borges et al., 2010; Brien \& Pigeat, 2007). Therefore, the existence of $\mathrm{Al}_{2} \mathrm{O}_{3}$ or even spinel $A l N O$ phases in samples cannot be discarded, but maybe in such a small proportions as to be detected by XRD.

$S 1, S 2$ and S5 show a higher crystalline quality than S3, S4 and S8. For these last samples, the extra $\mathrm{O}_{2}$ introduced to the chamber promotes the oxidation of the target-surface (target poisoning). In extreme cases when the target is heavily poisoned, oxidation can cause an arcing of the magnetron system. Formation of aluminium oxide on the target can act as an electrostatic shell, which in turn can affect the sputtering yield and the kinetic energy of species which impinge on substrate with a reduction of the sputtering rate: The lesser energy of species reacting on substrate, the lesser crystallinity of films.

Also, the oxygen can enter in to the AlN lattice through a mechanism involving a vacancy creation process by substituting a nitrogen atom in the weakest Al-N bond aligned parallel to [0001] direction. During the process, the mechanism of ingress of oxygen into the lattice is by diffussion (Brien \& Pigeat, 2007; Brien \& Pigeat, 2008; Jose et al., 2010). On the other hand, the ionic radius of oxygen $\left(r_{O}=0.140 \mathrm{~nm}\right)$ is almost ten times higher than that of nitrogen $\left(r_{N}=0.01-0.02 \mathrm{~nm}\right)$ (Callister, 2006). Thus, the oxygen causes an expansion of the crystal lattice through point defects. As the oxygen content increases, the density of point defects increases and the stacking of hexagonal AlN arrangement is disturbed . It has been reported that the $A l$ and $O$ atoms form octahedral atomic configurations that eventually become planar defects. These defects usually lie in the basal $\{001\}$ planes (Brien \& Pigeat, 2008; Jose et al., 2010).

As was mentioned, during the deposition of thin films, the oxygen competes with the nitrogen to form an oxidized Al-compound. The resulting films are then composed of separated phases of $A l N$ and $A l_{x} O_{y}$ domains. The presence of $A l_{x} O_{y}$ domains provokes a disruption in the preferential growth of the film.

For example, in $S 4$, the applied temperature of $120^{\circ} \mathrm{C}$ can promote an even more efficient diffusive ingress of oxygen into the AlN lattice and such temperature was not a factor contributing to improve crystallinity. In $S 3$ and $S 8$, oxygen by itself was the factor that provoked a film's low crystalline growth.

By using the Bragg angle $\left(\theta_{b}\right)$ as variable that satisfies the Bragg equation:

$$
2 d_{h k l} \operatorname{Sen} \theta_{b}=n \lambda
$$

and the formula applied for hexagonal systems:

$$
\frac{1}{d_{h k l}^{2}}=\frac{4}{3}\left(\frac{h^{2}+h k+k^{2}}{a^{2}}\right)+\frac{l^{2}}{c^{2}}
$$

the length of the lattice parameters " $a$ " and " $c$ " can then be obtained from the experimental data.

As films crystallized in a hexagonal würzite structure, $X R D$ patterns were processed with a software program in order to obtain the lattice parameters " $a$ " and " $c$ ". The AlN würzite structure from the JCPDS database (PDF file 00-025-1133, $c=4.97 \AA, a=3.11 \AA$ ) was taken as a 
reference (Powder Diffraction File, 1998). For the fitting, input parameters of $(h k l)$ planes with their corresponding theta-angle are given. By using the Bragg formula and the equation of distance between planes (for a hexagonal lattice), the lattice parameters are then calculated by using a multiple correlation analysis with a least squares minimization. The $2 \theta$ angles were set fixed while lattice parameters were allowed to fit. Calculated lattice parameters " $a$ " and " $c$ " and grain size " $L$ " by formula (4) are included in Table 2.

\begin{tabular}{|c|c|c|c|c|}
\cline { 2 - 5 } \multicolumn{1}{c|}{} & $\boldsymbol{a}$ & $\boldsymbol{c}$ & $\boldsymbol{c} / \boldsymbol{a}$ & $\boldsymbol{L}$ \\
\hline S1 & 3.11 & 4.99 & 1.60 & 21 \\
S2 & 3.11 & 4.98 & 1.60 & 23 \\
S3 & 3.13 & 5.0 & 1.59 & 21 \\
S4 & 3.14 & 5.0 & 1.59 & 20 \\
\hline S5 & 3.13 & 4.98 & 1.59 & 24 \\
S6 & 3.13 & 4.99 & 1.59 & 20 \\
S7 & 3.11 & 4.99 & 1.60 & 17 \\
S8 & 3.11 & 5.0 & 1.60 & 17 \\
\hline
\end{tabular}

Table 2. Lattice parameters " $a$ " (nm) and " $c$ " (nm) obtained from XRD measurements.

The average grain size " $L$ " is obtained through the Debye-Scherrer formula (Patterson, 1939):

$$
L=\frac{K \lambda}{B \cos \theta_{b}}
$$

where $K$ is a dimensionless constant that may range from 0.89 to 1.30 depending on the specific geometry of the scattering object.

For a perfect two dimenssional lattice, when every point on the lattice produces a spherical wave, the numerical calculations give a value of $K=0.89$. A cubic three dimensional crystal is best described by $\mathrm{K}=0.94$ (Patterson, 1939).

The measure of the peak width, the full width at half maximum (FWHM) for a given $\theta_{b}$ is denoted by $B$ (for a gaussian type curve).

From table 2, it can be observed that the calculated lattice parameters differ slightly from the ones reported from the JCPDS database, mainly the "c" value, particularly for $S 3, S 4$ and $S 8$. Introduction of oxygen into the AlN matrix along the $\{001\}$ planes also modifies the lattice parameters. As expected, the " $c$ " value is the most affected.

The quality of samples can also be evaluated from UV-Visible spectroscopy (Guo et al., 2006). By analysing the measured $T$ vs $\lambda$ spectra at normal incidence, the absorption coefficient $(\alpha)$ and the film thickness can be obtained.

If the thickness of the film is uniform, interference effects between substrate and film (because of multiple reflexions from the substrate/film interface) give rise to oscillations. The number of oscillations is related to the film thickness. The appearence of these oscillations on analized films indicates uniform thickness. If the thickness " $\mathrm{t}$ " were not uniform or slightly tappered, all interference effects would be destroyed and the $T$ vs $\lambda$ spectrum would look like a smooth curve (Swanepoel, 1983).

Oscillations are useful to calculate the thickness of films using the formula (Swanepoel, 1983; Zong et al., 2006): 


$$
t=\frac{1}{2 n\left(\frac{1}{\lambda_{2}}-\frac{1}{\lambda_{1}}\right)}
$$

Where $t$ is the thickness of film, $n$ the refractive index, $\lambda_{1}$ and $\lambda_{2}$ are the wavelength of two adjacent peaks. Calculated optical thickness of samples using the above mentioned formula, are included in Tables 1(a) and (b).

Regarding the absorbance ( $\alpha$ ), a $T$ vs $\lambda$ curve can be divided (grossly) into four regions. In the transparent region $\alpha=0$ and the transmitance is a function of $n$ and $t$ through multiple reflexions. In the region of weak absorption $\alpha$ is small and the transmission starts to reduce. In the region of medium absorption the transmission experiences the effect of absoption even more. In the region of strong absorption the transmission decreases abruptly. This last region is also named the absorption edge.

Near the absorption edge, the absorption coefficient can expressed as:

$$
h v \alpha=\beta\left(h v-E_{g}\right)^{\gamma}
$$

where $h v$ is the photon energy, $E_{g}$ the optical band gap and $\gamma$ is the parameter measuring the type of band gap (direct or indirect) (Guerra et al., 2011; Zong et al., 2006).

Thus, the optical band gap is determined by applying the Tauc model and the Davis and Mott model in the high absorbance region. For AlN films, the transmittance data provide the best linear curve in the band edge region, taking $n=1 / 2$, implying that the transition is direct in nature (for indirect transition $\mathrm{n}=2$ ). Band gap is obtained by plotting $(\alpha h v)^{2}$ vs $h v$ by extrapolating the linear part of the absorption edge to find the intercept with the energy axis. By using UV-Vis measurements for AlNO films on glass sustrates, authors of ref. (Jang et al., 2008) found band gap values between 6.63 to $6.95 \mathrm{eV}$, depending the Ar:O ratio.

From our measurements, figure 4 displays the optical spectra ( $T$ vs $\lambda$ curve) graphs. The oscillations detected in the curves attest the high quality in homogeneity of deposited films. All the samples have oscillation regardless their degree of crystallinity. An important feature to note is that curves present differences in the "sharpness", at the onset of the strong absorption zone. These differences are attributed to deposition conditions, where final density of films, presence of deffects and thickness, modify the shape of the curve at the band edge.

A FESEM micrograph cross-section of $S 2$ is displayed on figure 5. From figure, it is possible to identify a well defined substrate/film interface and a section of film with homogeneous thickness. Together with micrographs, in-situ EDAX analyses were conducted in two specific regions of the film. An elemental analysis by EDAX allows to distinguish the differences in elemental concentration depending on the analized zone. In the film zone, an elemental concentration of $A l(54.7 \%)$ and $N(45.2 \%)$ was detected, as expected for AlN film. Conversely, in the substrate zone, elemental concentration of $\mathrm{Si}$ and $\mathrm{O}$ with traces of $\mathrm{Ca}, \mathrm{Na}$, $\mathrm{Mg}$ was detected, as expected for glass.

At this stage, we can establish that during the sputtering process, the oxygen diffuses in to the growing $A l N$ films. Then, the oxygen attaches to available $\mathrm{Al}$, forming $\mathrm{Al}_{\mathrm{x}} \mathrm{O}_{\mathrm{y}}$ phases. Dominions of these phases, contained in the whole film, can induce defects. These defects are piled up along the c-axis. From X-ray diffractograms, a low and narrow intensity at the (0002) reflection indicates low crystallographic ordering. By calculating lattice parameters 
"a" and "c" and evaluating how far their obtained values deviate from the JCPDF standard (mainly the " $c$ " distance), also provides evidence about the degree of crystalline disorder. In films, a low crystallographic ordering does not imply a disruption in the homogeneity, as was already detected by UV-Visible measurements. A more detailed analysis concerning the identification and nature of the phases contained in films were performed with a spectroscopic technique.
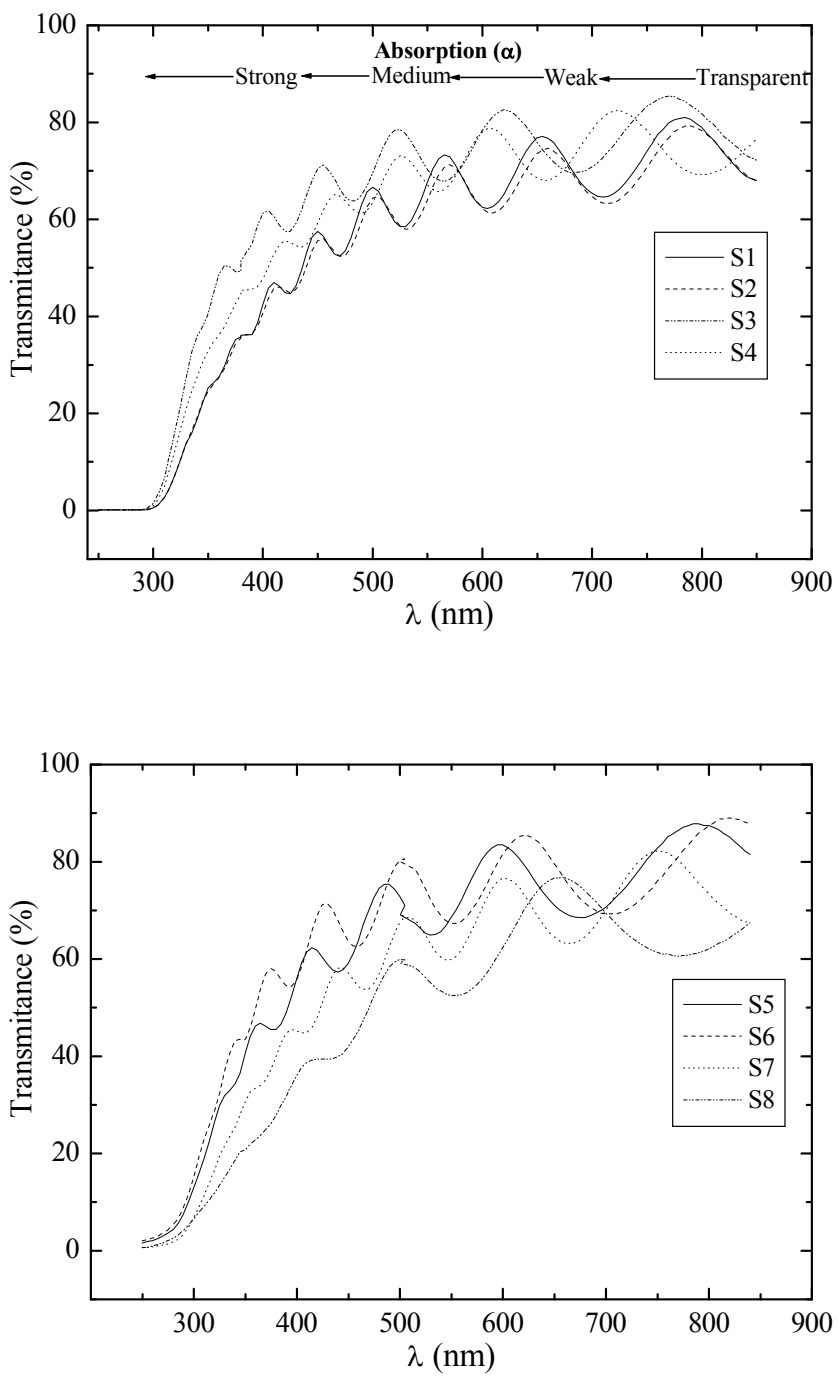

Fig. 4. Optical transmission spectra of deposited films. 

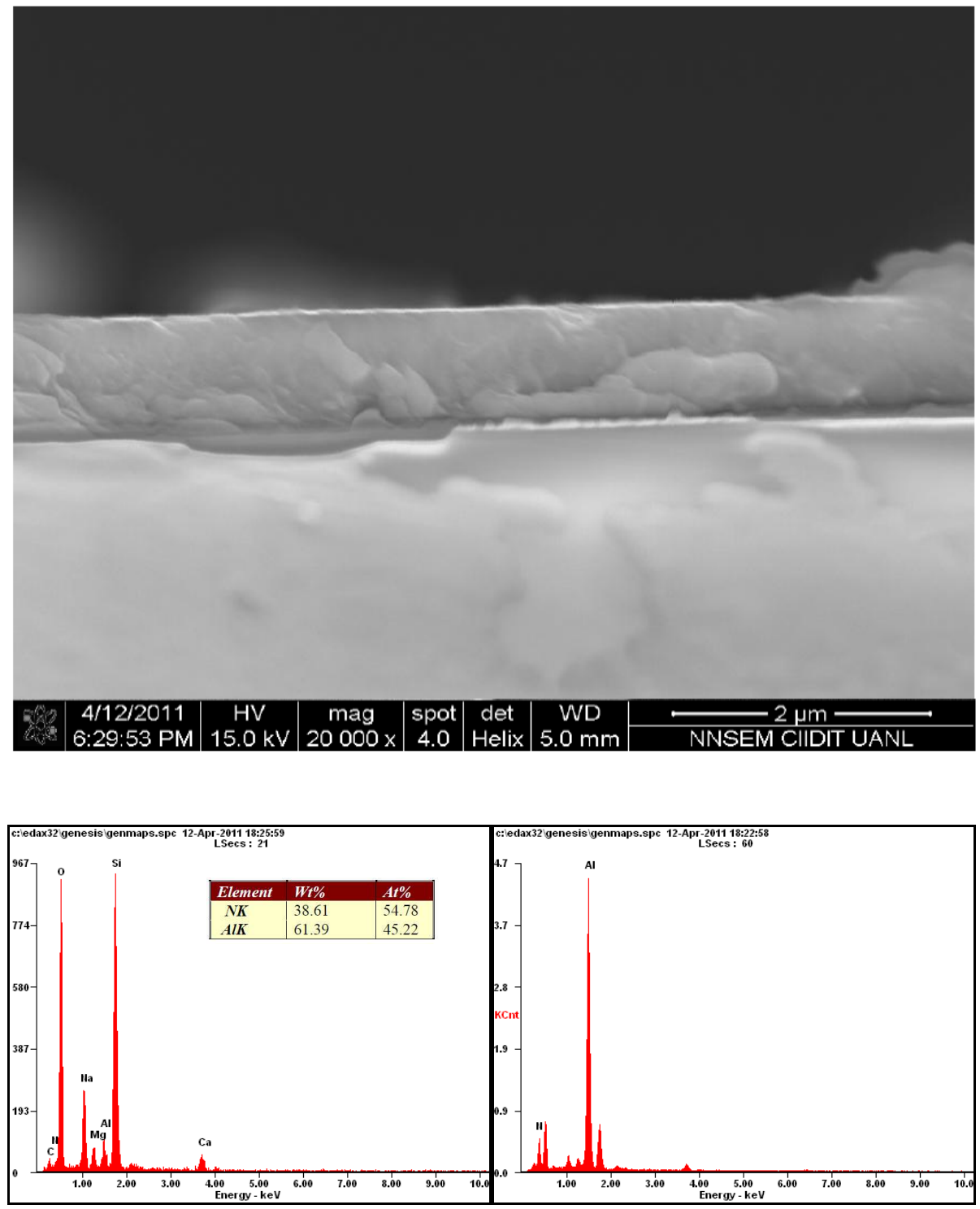

Fig. 5. Cross section FESEM micrograph of AlN film (S2). An homogeneous film deposition can be observed. In the right column an EDAX analysis of (a) film zone and (b) substrate zone is included. 


\section{Chemical characterization}

The process of oxidation is a micro chemical event that was not completely detected by $X R D$. Because of that, XPS analyses were performed in order to detect and identify oxidized phases.

XPS measurements were obtained with a Perkin-Elmer PHI 560/ESCA-SAM system, equipped with a double-pass cylindrical mirror analyzer, and a base pressure of $1 \times 10^{-9}$ Torr. To clean the surface, $A r^{+}$sputtering was performed with $4 \mathrm{keV}$ energy ions and $0.36 \mu \mathrm{A} / \mathrm{cm}^{2}$ current beam, yielding to about $3 \mathrm{~nm} / \mathrm{min}$ sputtering rate. All XPS spectra were obtained after $\mathrm{Ar}^{+}$sputtering for $15 \mathrm{~min}$. The use of relatively low current density in the ion beam and low sputtering rate reduces modifications in the stoichiometry of the AlN surface. For the XPS analyses, samples were excited with $1486.6 \mathrm{eV}$ energy $\mathrm{Al}_{\mathrm{K} \alpha} \mathrm{X}$-rays. XPS spectra were obtained under two different conditions: (i) a survey spectrum mode of 0-600 eV, and (ii) a multiplex repetitive scan mode. No signal smoothing was attempted and a scanning step of $1 \mathrm{eV} /$ step and $0.2 \mathrm{eV} / \mathrm{step}$ with an interval of $50 \mathrm{~ms}$ was utilized for survey and multiplex modes, respectively. The spectrometer was calibrated using the $\mathrm{Cu} 2 p_{3 / 2}(932.4 \mathrm{eV})$ and $\mathrm{Cu}$ $3 p_{3 / 2}(74.9 \mathrm{eV})$ lines. Al films deposited on the glass and silica substrates were used as additional references for Binding energy. In both kind of films, the BE of metallic $\left(A l^{\circ}\right) A l 2 p$ transition gave a value of $72.4 \mathrm{eV}$ respectively. On these films, the $C 1$ s-transition gave values of $285.6 \mathrm{eV}$ and $285.8 \mathrm{eV}$ for glass and silica substrates, respectively. These values were set for $B E$ of $C 1$ s. The relative atomic concentration of samples was calculated from the peak area of each element $(A l 2 p, O 1 s, N 1 s)$ and their corresponding relative sensitivity factor values (RSF). These RSF were obtained from software system analysis (Moulder, 1992). Gaussian curve types were used for data fitting.

Figure 6 displays the XPS spectra of films. The elemental attomic concentration (atomic percent) calculated from the $O 1 s, N 1 s$ and $A l 2 p$ transitions is also included in the figure. Figure 6 a shows the $A l 2 p$ high-resolution photoelectron spectrum of S1. The binding energies (BE) from the acquired Al2p photoelectron transition are presented in table 3.

The survey spectra show the presence of oxygen in all films, regardless of the fact that some samples were grown without oxygen during deposition. From the XPS analysis, S2 and S5, our films with the best crystalline properties, a concentration of oxygen of $26.3 \%$ and $21.6 \%$ atomic percent respectively, was measured. The highest measured concentration of oxygen was of about $36.6 \%$, corresponding to S8. This occurrence of oxidation was not directly detected by the XRD analysis, since these oxidized phases can be spread in a low amount throughout the film.

The nature of these phases can be inferred from the deconvoluted components of the $A l 2 p$ transition. In Figure $6 a$, the $A l 2 p$ core level spectrum is presented. This spectrum is composed of contributions of metallic $A l(B E=72.4 \mathrm{eV})$, nitridic $A l$ in $A l N(B E=74.7 \mathrm{eV})$ and oxidic $\mathrm{Al}$ in $\mathrm{Al}_{2} \mathrm{O}_{3}(\mathrm{BE}=75.6 \mathrm{eV})$.

Despite the differences in experimental conditions, aluminium reacted with the nitrogen and the oxygen in different proportions. Even in S2, the thin film with the best crystalline properties, a proportion of about $30.6 \%$ of aluminum reacted with oxygen to form an aluminium oxide compound. In $S 7$, the relative contribution of $A l$ in nitridic and oxidic state is almost similar, of $42.2 \%$ and $49.5 \%$, respectively. A tendency, not absolute but in general, indicates that the higher the proportion of $A l$ in oxidic state, the more amorphous the film. 


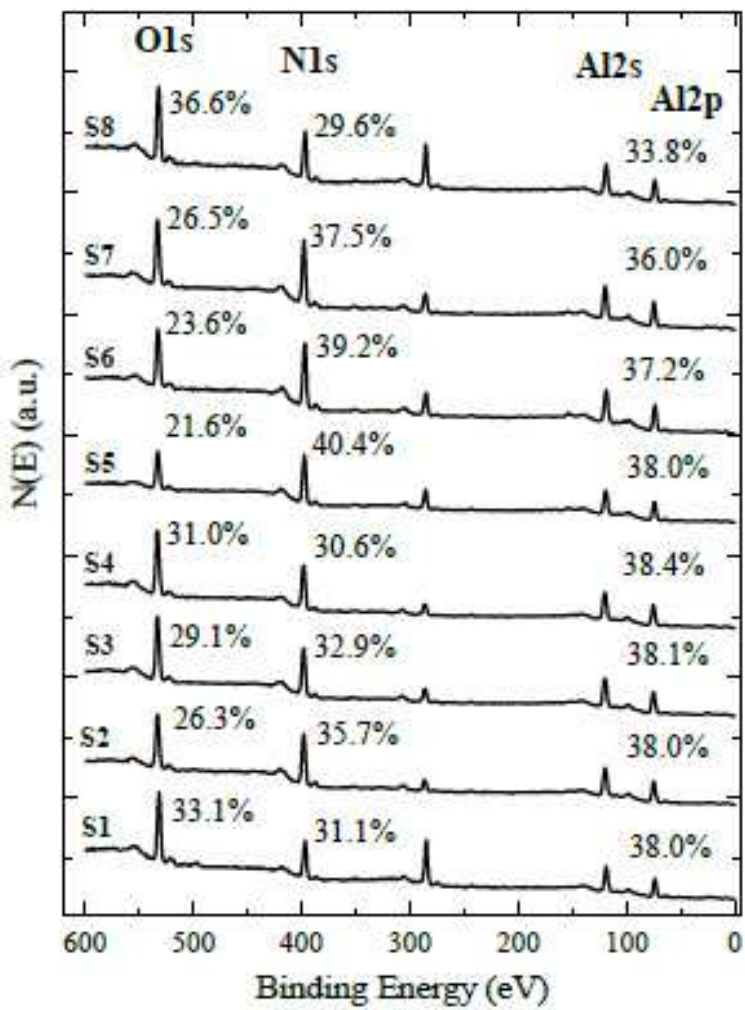

Fig. 6. XPS survey spectra of $d c$ sputtered films. In this figure, the O1s, N1s and $A l 2 p$ corelevel principal peaks can be observed.

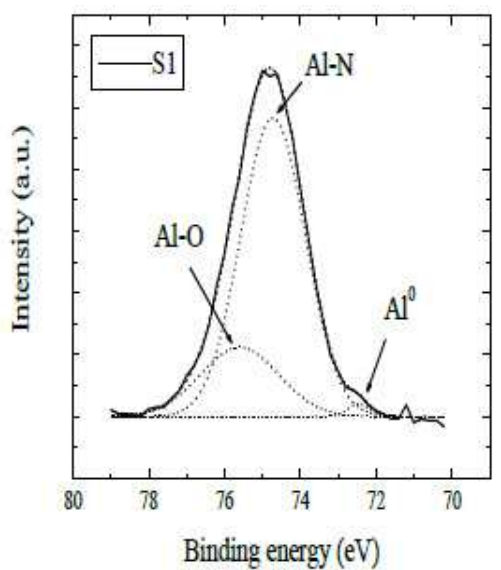

Fig. 6a. Al2p XPS spectrum of $S 1$. The $A l 2 p$ peak is composed of contributions of metallic aluminium $(A l O)$, aluminium in nitride $(A l-N)$ and oxidic $(A l-O)$ state. 


\begin{tabular}{|c|ccc|cc|c|}
\cline { 2 - 6 } \multicolumn{1}{c|}{} & \multicolumn{3}{c|}{ Binding energy (eV) } & \multicolumn{2}{c|}{ Contribution (\%) } & \multicolumn{1}{c}{} \\
\cline { 2 - 7 } \multicolumn{1}{c|}{} & $A l^{0}$ & $A l-N$ & $A l-O$ & $A l-N$ & $A l-O$ & $\Delta E(\mathrm{eV})$ \\
\hline S1 & 72.4 & 74.7 & 75.6 & 77.3 & 21.6 & 0.9 \\
S2 & & 74.7 & 75.7 & 69.3 & 30.6 & 1.0 \\
S3 & & 74.7 & 75.2 & 74.7 & 22.9 & 0.5 \\
S4 & 72.1 & 74.4 & 75.1 & 58.4 & 39.9 & 0.7 \\
\hline \hline S5 & & 74.7 & 75.5 & 64.4 & 35.1 & 0.8 \\
S6 & 72.6 & 74.7 & 75.5 & 60.2 & 37.3 & 0.8 \\
S7 & & 74.7 & 75.4 & 42.2 & 49.5 & 0.7 \\
S8 & & 74.4 & 75.5 & 58.7 & 36.3 & 1.1 \\
\hline
\end{tabular}

Table 3. Binding energy $(\mathrm{eV})$ of metallic aluminium $\left(A l^{\circ}\right)$, aluminium in nitridic $(A l-N)$ and oxidic $(A l-O)$ state obtained from deconvoluted components of $A l 2 p$ transition. Percentage (relative \%) of $A l$ bond to $N$ and $O$ is also displayed.

For comparison purposes, some relevant literature concerning the binding energies of metallic- $\mathrm{Al}, \mathrm{AlN}$ and $\mathrm{Al}_{2} \mathrm{O}_{3}$ has been reviewed and included in table 4. Aluminium in metallic state lies in the range of $72.5-72.8 \mathrm{eV}$. Aluminium in nitridic state lies in the range of 73.1$74.6 \mathrm{eV}$, while aluminium in oxidic state lies in the range of $74.0-75.5 \mathrm{eV}$. Also, there is an $\mathrm{Al}$ $\mathrm{N}-\mathrm{O}$ spinel-like bonding, very similar in nature to oxidic aluminium with a BE value of 75.4 $\mathrm{eV}$. Another criteria used by various authors for phase identification, is to take the difference $(\Delta E)$ in $B E$ of the $A l 2 p$ transition corresponding to $A l-N$ and $A l-O$ bonds. This difference can take values of about $0.6 \mathrm{eV}$ up to $1.1 \mathrm{eV}$ (see Table 4).

\begin{tabular}{|c|c|c|c|c|}
\hline \multicolumn{3}{|c|}{ Binding energy $(\mathrm{eV})$} & & \multirow[b]{2}{*}{ References } \\
\hline$A l^{0}$ & $A l-N$ & $A l-O$ & $\Delta E(\mathrm{eV})$ & \\
\hline 72.8 & $\begin{array}{l}74.1 \\
74.3\end{array}$ & $\begin{array}{l}74.7 \\
75.2\end{array}$ & $\begin{array}{l}0.6 \\
0.9\end{array}$ & (Stanca, 2004) \\
\hline & 74.6 & 75.4 (spinel) & 0.8 & (Sohal et al., 2006) \\
\hline 72.8 & $\begin{array}{l}74.1 \\
73.6\end{array}$ & $\begin{array}{l}74.7 \\
74.6\end{array}$ & $\begin{array}{l}0.7 \\
1.0\end{array}$ & (Jose et al., 2010) \\
\hline 72.8 & 74.4 & 75.2 & 0.8 & (Wang et al., 1997) \\
\hline $\begin{array}{l}72.7 \\
72.8 \\
72.5\end{array}$ & $\begin{array}{l}74.5 \\
74.6\end{array}$ & $\begin{array}{l}75.5 \\
75.6\end{array}$ & $\begin{array}{l}1.0 \\
1.0\end{array}$ & (Gredelj et al., 2001) \\
\hline & 73.1 & $\begin{array}{c}75.1 \\
74.2 \text { (spinel) }\end{array}$ & $\begin{array}{l}2.0 \\
1.1\end{array}$ & (Richthofen et al., 1996) \\
\hline
\end{tabular}

Table 4. Binding energy of $(\mathrm{eV})$ of metallic aluminium $(A l O)$, aluminium in nitridic $(A l-N)$ and oxidic $(A l-O)$ state obtained from literature 
In films, only small traces of metallic aluminium were detected in $S 1$ at $72.4 \mathrm{eV}$. For $S 4$ and $S 8, B E$ of $A l$ in nitride gave a value of $74.4 \mathrm{eV}$, just below the $B E$ of $74.7 \mathrm{eV}$, detected for the rest of the samples. This value of $74.4 \mathrm{eV}$ can be attributed to a substoichiometric $A l N_{x}$ phase (Robinson et al., 1984; Stanca, 2004). On the other hand, the BE for aluminium in oxydic state varies from $75.1 \mathrm{eV}$ to $75.7 \mathrm{eV}$. The lowest values of $B E$ of about $75.1 \mathrm{eV}$ and $75.2 \mathrm{eV}$, corresponding to $S 3$ and $S 4$, respectively, could be attributed to a substoichiometric $A l_{x} O_{y}$ phase, although in our own experience, the reaction of aluminium with oxygen tends to form the stable $\gamma-\mathrm{Al}_{2} \mathrm{O}_{3}$ phase, which possesses somewhat higher value in $B E$. These finding agree with those reported in other works, where low oxidation states such as $\mathrm{Al}^{+1}, \mathrm{Al}^{+2} \mathrm{can}$ be found at a $B E$ lower than the one of $A l^{+3}$ (Huttel et al., 1993; Stanca, 2004). Oxidation states lower than +3 confer an amorphous character to the aluminium oxide (Gutierrez et al., 1997).

\section{Theoretical calculations}

Experimental results provided evidence that oxygen can induce important modifications in the structural properties of sputtered-deposited AlN films. In this way, theoretical calculations were performed to get a better understanding of how the position of the oxygen into the $A l N$ matrix can modify the electronic properties of the film system.

The bulk structure of hexagonal AlN was illustrated in Figure 1. Additionally, hexagonal $\mathrm{AlN}$ can be visualized as a matrix of distorted tetrahedrons. In a tetrahedron, each $\mathrm{Al}$ atom is surrounded by four $\mathrm{N}$ atoms. The four bonds can be categorized into two types. The first type is formed by three equivalent Al-Nx, $(x=1,2,3)$ bonds, on which the $\mathrm{N}$ atoms are located in the same plane normal to the [0001] direction. The second type is the Al- $\mathrm{N}_{0}$ bond, on which the $\mathrm{Al}$ and $\mathrm{N}$ atoms are aligned parallel to the [0001] direction (see figure 7). This last bond is the most ionic and has a lower binding energy than the other three (Chaudhuri et al., 2007; Chiu et al., 2007; Zhang et al, 2005). When an AlN film is oxidized, the oxygen atom can substitute the nitrogen atom in the weakest Al-N0 bond while the displaced nitrogen atom can occupy an interstitial site in the lattice (Chaudhuri et al., 2007). For würzite AlN, there are four atoms per hexagonal unit cell where the positions of the atoms for $\mathrm{Al}$ and $\mathrm{N}$ are: $\mathrm{Al}(0,0,0),(2 / 3,1 / 3,1 / 2) ; \mathrm{N}(0,0, \mathrm{u}),(2 / 3,1 / 3, \mathrm{u}+1 / 2)$, where " $\mathrm{u}$ " is a dimensionless internal parameter that represents the distance between the Al-plane and its nearest neighbor N-plane, in the unit of " $c$ ", according to the JCPDS database (Powder diffraction file, 1998).

The calculations were perfomed using the tight-binding method (Whangbo \& Hoffmann, 1978) within the extended Hückel framework (Hoffmann, 1963) using the computer package YAeHMOP (Landrum, 1900). The extended Hückel method is a semiempirical approach that solves the Schrödinger equation for a system of electrons based on the variational theorem (Galván, 1998). In this approach, explicit correlation is not considered except for the intrinsic contributions included in the parameter set. For a best match with the available experimental information, experimental lattice parameters were used instead of optimized values. Calculations considered a total of 16 valence electrons corresponding to 4 atoms within the unit cell for AlN.

Band structures were calculated using 51 k-points sampling the first Brillouin zone (FBZ). Reciprocal space integration was performed by $k$-point sampling (see figure 8 ). From band structure, the electronic band gap $\left(E_{g}\right)$ was obtained. 

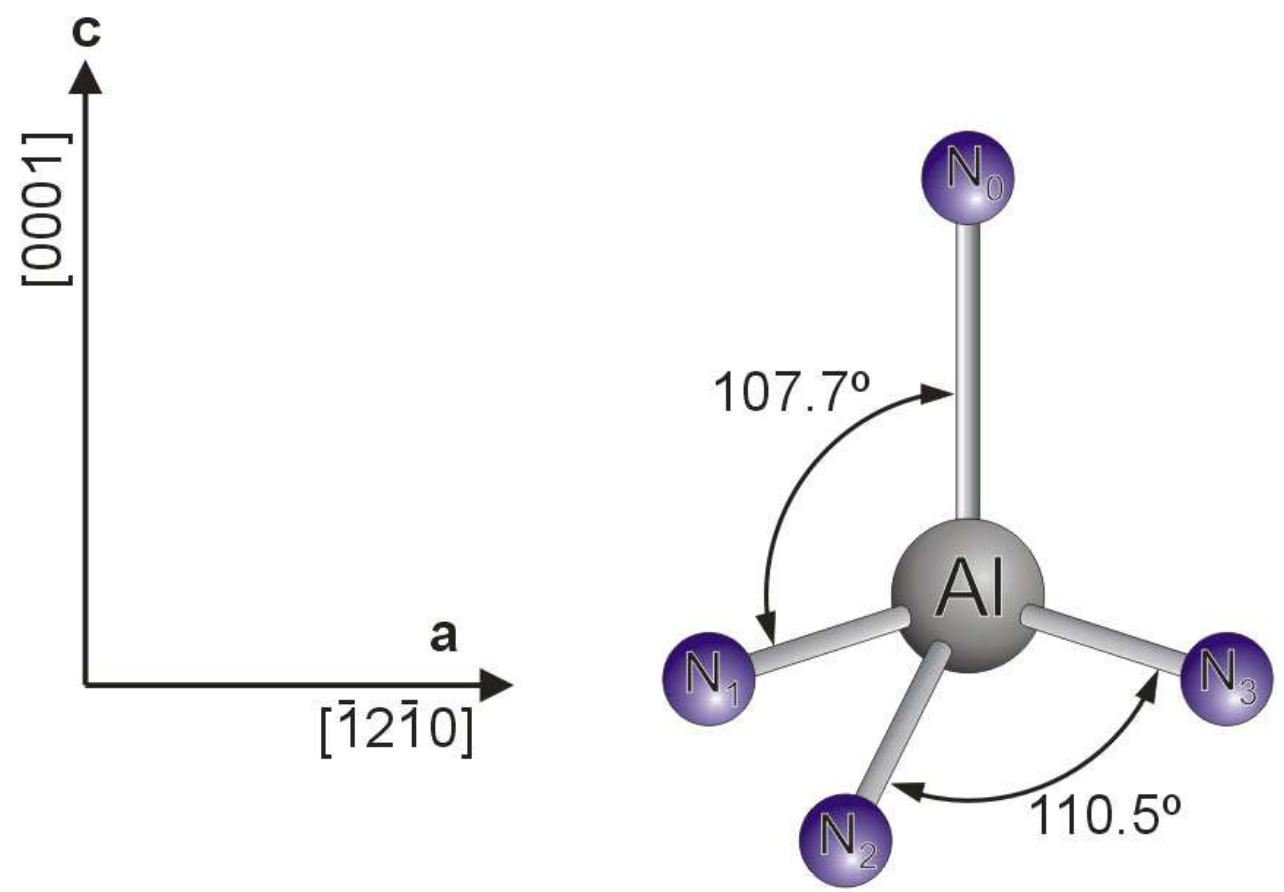

Fig. 7. Individual tetrahedral arrangement of hexagonal AlN.

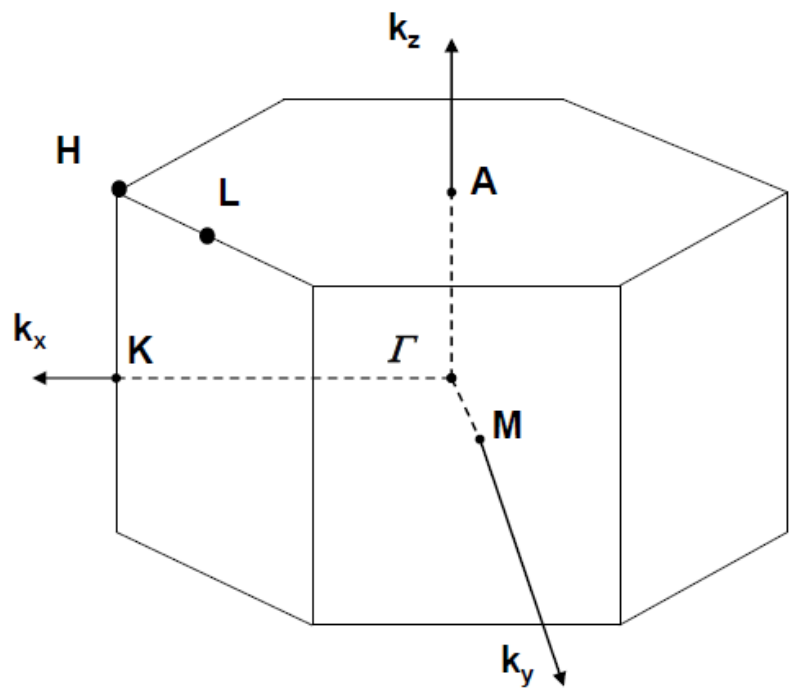

Fig. 8. Hexagonal lattice in k-space. 
Calculations were performed considering four scenarios:

1. A wurzite-like $A l N$ structure with no oxygen in the lattice

2. An oxygen atom inside the interstitial site of the tetrahedral arrangement (interstitial)

3. An oxygen atom in place of the $N$ atom in the weakest $A l-N_{0}$ bond (substitution)

4. An oxygen atom on top of the AlN surface (at the surface).

Theoretical band-gap calculations are summarized in Table 5. Values are given in electron volts $(\mathrm{eV})$.

\begin{tabular}{|l|c|}
\cline { 2 - 2 } \multicolumn{1}{c|}{} & Energy gap (eV) \\
\hline (1) AlN Hexagonal & $7.2-\operatorname{Direct} M$ \\
\hline (2) Interstitial $O$ & $1.3-\operatorname{Direct} M$ \\
\hline (3) Substitution of $N$ by $O$ & $0.82-\operatorname{Direct} H$ \\
\hline (4) Surface $O$ & $6.2-$ Indirect $\Gamma-M$ \\
\hline
\end{tabular}

Table 5. Calculated energy gaps for pure AlN (würzite) and with oxygen in different atomic site positions.

For AlN hexagonal, a direct band gap of $\approx 7.2 \mathrm{eV}$ at $M$ was calculated (see Figure 9). When oxygen was taken into account in the calculations, the band gap value undergoes a remarkable change: $1.3 \mathrm{eV}$ for $A l N$ with intercalated oxygen (2) and $0.8 \mathrm{eV}$ for AlN with oxygen substitution (3). In terms of electronic behavior, the system transformed from insulating $(7.2 \mathrm{eV})$ to semiconductor $(1.3 \mathrm{eV})$, and then from semiconductor $(1.3 \mathrm{eV})$ to semimetal $(0.82 \mathrm{eV})$.

This change in the electronic properties is explained by the differences between the ionic radius of Nitrogen $\left(r_{N}\right)$ and Oxygen $\left(r_{O}\right)$. The ionic radius of the materials involved was: $r_{N}=0.01-0.02 \mathrm{~nm}, r_{O}=0.140 \mathrm{~nm}$ (Callister, 2006). Comparing these values, it can be noted that $r_{O}$ is almost ten times higher than $r_{N}$. This fact would imply that when the oxygen atom takes the place of the nitrogen atom (by substitution o intercalation of $O$ ), the crystalline lattice expands because of the larger size of oxygen. Any change in the distance among atoms and the extra valence electron of the oxygen will alter the electronic interaction and in consequence, the band gap value

In calculation (4), the atoms of $A l$ and $N$ are kept in their würzite atomic positions while the oxygen atom is placed on top of the AlN lattice. In this case, the calculated band gap (6.31 $\mathrm{eV})$ is closer in value to pure $\operatorname{AlN}(7.2 \mathrm{eV})$ than the calculated ones for interstitial $(1.3 \mathrm{eV})$ and substitution $(0.82 \mathrm{eV})$. In this case, theoretical results predicts that when the oxygen is not inside the Bravais lattice, the band gap will be close in value to the one of hexagonal $A I N$; conversely, the more the oxygen interacts with the AlN lattice, the more changes in electronical properties are expected; However, in energetic terms, competition between $N$ and $O$ atoms to get attached to the $A l$ to form separated phases of $A l N$ and $A l_{x} O_{y}$ is the most probable configuration, as far as experimental results suggests.

Theoretical calculations of band structure for würzite AlN have been performed using several approaches; For comparison purposes, some of them are briefly described in Table 6 . 


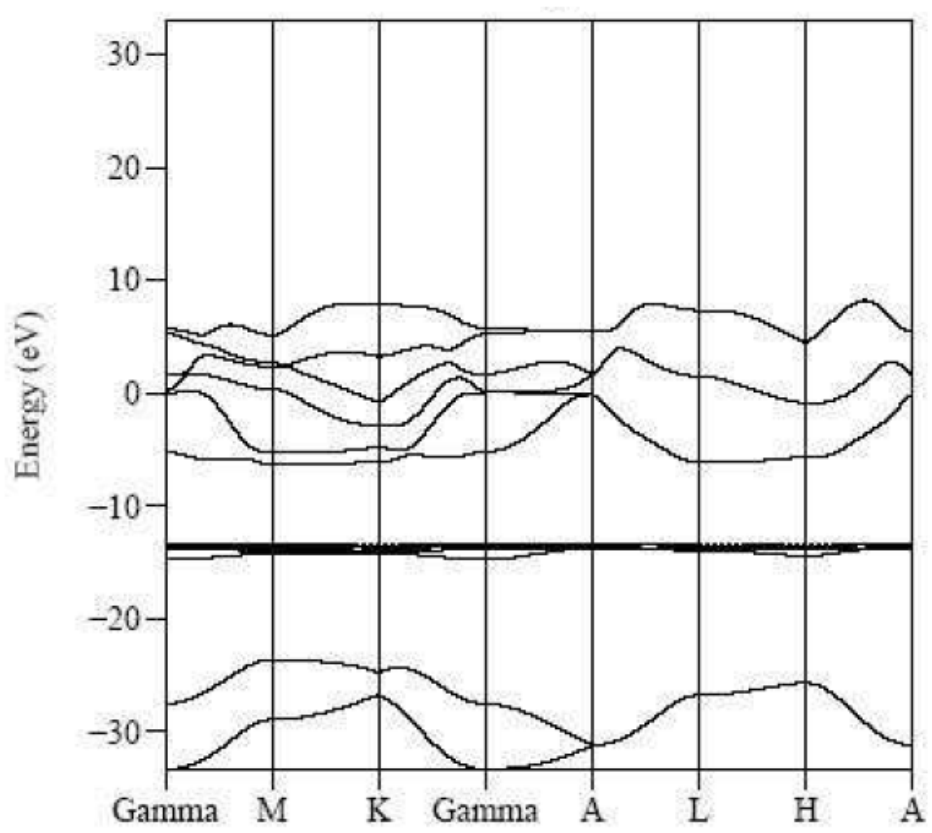

Fig. 9. Band structure for $2 \mathrm{H}-\mathrm{AlN}$ hexagonal, sampling the first Brillouin zone (FBZ).

\begin{tabular}{|c|l|c|}
\hline $\begin{array}{c}\text { Energy } \\
\text { band gap } \\
(\mathbf{e V})\end{array}$ & \multicolumn{1}{|c|}{ Method/Procedure } & Reference \\
\hline 6.05 & $\begin{array}{l}\text { Local density approximation (LDA) within the } \\
\text { density functional theory (DFT) with a correction } \\
\Delta \mathrm{g} \text {, using a quasi-particle method: LDA+ } \mathrm{g}\end{array}$ & $\begin{array}{c}\text { (Ferreira et al., } \\
\text { 2005) }\end{array}$ \\
\hline 6.2 & $\begin{array}{l}\text { Empirical pseudopotential method (EPM). An } \\
\text { analytical function using a fitting procedure for both } \\
\text { symmetric and antisymmetric parts, and a potential } \\
\text { is constructed }\end{array}$ & $\begin{array}{c}\text { (Rezaei et al., } \\
\text { 2006) }\end{array}$ \\
\hline 4.24 & $\begin{array}{l}\text { Full potential linear muffin-tin orbital (FPLMTO) } \\
\text { (Persson et al., } \\
\text { 2005) }\end{array}$ \\
\hline 6.15 & FPLMTO with a corrected band gap $\Delta \mathrm{g}$ & $\begin{array}{c}\text { (Persson et al., } \\
\text { 2005) }\end{array}$ \\
\hline
\end{tabular}

Table 6. AlN energy band gap values obtained from theoretical calculations. 
From our results, the calculated band gap for AlN was $7.2 \mathrm{eV}$ : slightly different to the reported experimental-value of $\approx 6.2 \mathrm{eV}$. About this issue, is important to take into account that in our calculations spin-orbit effects were not considered. Therefore, some differences arise, especially when an energy-band analysis is performed. Some bands could be shifted up or down in energy due to these contributions. However, it must be stressed out that our proposed method is simple, computationally efficient and the electronic structures obtained can be optimized to closely match the experimental and/or ab-initio results. More specific details about DOS graphs and PDOS calculations can be found in reference (García-Méndez et al., 2009), of our authorship.

\section{Conclusions}

In this chapter, the basis of $D C$ reactive magnetron sputtering as well as experimental results concerning the growth of $A l N$ thin films has been reviewed.

For instance, films under investigation were polycrystalline and exhibit an oriented growth along the [0002] direction. XRD measurements showed that films are composed mainly by crystals of hexagonal AlN. From XPS measurements, traces of aluminium oxides phases were detected. Films deposited without flux of oxygen presented the best crystalline properties, although phases of aluminum oxide were detected on them too. In this case, even in high vacuum, ppm levels of residual oxygen can subside and react with the growing film. Oxygen induces on films structural disorder that tends to disturb the preferential growth at the c-axis.

In other works of reactive magnetron sputtering, authors of ref. (Brien \& Pigeat, 2008) found that for contamination of oxygen atoms (from $5 \%$ to $30 \%$ atomic), AlN films can still grow in würzite structure at room temperature, with no formation of crystalline AlNO or $\mathrm{Al}_{2} \mathrm{O}_{3}$ phases, just only traces of amorphous $\mathrm{AlO}_{x}$ phases, that leave no signature in diffraction recordings, which is consistent with our results, where a dominant AlN phase in the whole film was detected. On the other hand, authors of ref. (Jose et al., 2010) reports that even in high vacuum, ppm levels of oxygen can stand and promote formation of alumina-like phases at the surface of AlN films, where these phases of alumina could only be detected and quantified by XPS and conversely, X-ray technique was unable to detect. In other report, authors of ref. (Borges et al., 2010), stablished three regions: Metallic (zone M), transition (zone T) and compound (zone C), where chemical composition of AlNO films varies depending the reactive gas mixture in partial pressure of $\mathrm{N}_{2}+\mathrm{O}_{2}$ at a fixed $\mathrm{Ar}$ gas partial pressure. Then, they found that when film pass from zone $M$ to zone $C$, films grow from crystalline-like to amorphous-type ones, and the lattice parameters increase as more oxygen and nitrogen is incorporated into the films, which also represents the tendency we report in our results.

Thus, the versatility of the reactive $D C$ magnetron sputtering that enables the growth of functional and homogeneous coatings in this case AlN films has been highlighted. To produce suitable films, however, it is necessary to identify the most favourable deposition parameters that maximize the sputtering yield, in order to get the optimal deposition rate: the sputter current that determines the rate of deposition process, the applied voltage that determines the maximum energy at which sputtered particles escape from target, the pressure into the chamber that determines the mean free path for the sputtered material, 
together with the target-substrate distance that both determines the number of collisions of particles on their way to the substrate, the gas mixture that determines the stoichiometry, the substrate temperature, all together influence the crystallinity, homogeneity and porosity of deposited films. As the physics behind the sputtering process and plasma formation is not simple, and many basic and technological aspects of the sputtering process and AlN film growth must be explored (anisotropic films, preferential growth, band gap changes), further investigation in this area is being conducted.

\section{Acknowledgment}

This work was sponsored by PAICyT-UANL, 2010.

\section{References}

Moreira, M.A.; Doi, I; Souza, J.F.; Diniz, J.A. (2011). Electrical characterization and morphological properties of AlN films prepared by dc reactive magnetron sputtering. Microelectronic Engineering, Vol. 88, No. 5, (May 2011), pp. 802-806, ISSN 0167-9317

Morkoç, H. (2008) Handbook of Nitride Semiconductors and Devices, Vol. 1: Materials Properties, Physics and Growth (2008) Weinheim Wiley-VCH. ISBN 978-3-52740837-5, Weinheim, Germany.

Chaudhuri, J.; Nyakiti, L.; Lee, R.G.; Gu, Z.; Edgar, J.H.; Wen, J.G. (2007). Thermal oxidation of single crystalline aluminium nitride. Materials Characterization, Vol. 58, No. 8-9, (August 2007), pp. 672-679, ISSN 1044-5803

Chiu, K.H.; Chen, J.H.; Chen, H.R.; Huang, R.S. (2007). Deposition and characterization of reactive magnetron sputtered aluminum nitride thin films for film bulk acoustic wave resonator. Thin Solid Films, Vol. 515, No. 11, (April 2007), pp. 4819-4825, ISSN 0040-6090

Jang, K.; Lee, K.; Kim, J.; Hwang, S.; Lee, J.; Dhungel, S.K.; Jung, S.; Yi, J. (2006). Effect of rapid thermal annealing of sputtered aluminium nitride film in an oxygen ambient. Mat Sci Semicon Proc, Vol. 9, No. 6, (December 2006), pp. 1137-1141, ISSN 1369-8001

Kar, J.P.; Bose, G.; Tuli, S. (2006). A study on the interface and bulk charge density of AlN films with sputtering pressure. Vacuum, Vol. 81, No. 4, (November 2006), pp. 494498, ISSN 0042-207X

Olivares, J.; González-Castilla, S.; Clement, M.; Sanz-Hervás, A.; Vergara, L.; Sangrador, J.; Iborra, E. (2007). Combined assessment of piezoelectric AlN films using X-ray diffraction, infrared absorption and atomic force microscopy. Diamond $\mathcal{E}$ Related Materials, Vol. 16, No. 4-7, (April 2007), pp. 1421-1424, ISSN 0925-9635

Prinz, G.M.; Ladenburger, A; Feneberg, M.; Schirra, M.; Thapa, S.B.; Bickermann, M.; Epelbaum, B.M.; Scholz, F.; Thonke, K.; Sauer, R. (2006). Photoluminescence, cathodoluminescence, and reflectance study of AlN layers and AlN single crystals. Superlattices \& Microstructures, Vol. 40, No. 4-6, (December 2006), pp. 513-518, ISSN 0749-6036 
Jose, F.; Ramaseshan, R.; Dash, S.; Tyagi, A.K.; Raj, B. (2010). Response of magnetron sputtered AlN films to controlled atmosphere annealing. Journal of Physics D: Applied Physics, Vol. 43, No. 7, (February 2010), pp. 075304-10, ISSN 00223727

Brien, V.; Pigeat, P. (2008). Correlation between the oxygen content and the morphology of AlN films grown by r.f. magnetron sputtering. Journal of Crystal Growth, Vol. 310, No. 16, (August 2008), pp. 3890-3895, ISSN 0022-0248

Jang, K.; Jung, S.; Lee, J.; Lee, K.; Kim, J.; Son, H.; Yi, J. (2008). Optical and electrical properties of negatively charged aluminium oxynitride films. Thin Solid Films, Vol. 517, No. 1, (November 2008), pp. 444-446, ISSN 0040-6090

Borges, J.; Maz, F.; Marques, L. (2010). AlNxOy thin films deposited by DC reactive magnetron sputtering. Applied Surface Science, Vol. 252, No. 257, No. 5, (December 2010), pp. 1478-1483, ISSN 0169-4332

Ianno, N.J.; Enshashy, H.; Dillon, R.O. (2002). Aluminum oxynitride coatings for oxidation resistance of epoxy films. Surface and Coatings Technology, Vol. 155, No. 2-3, (June 2002), pp. 130-135, ISSN 0257-8972

Erlat, A.G.; Henry, B.M.; Ingram, J.J.; Mountain, D.B.; McGuigan, A.; Howson, R.P.; Grovenor, C.R.M.; Briggs, G.A.D.; Tsukahara, T. (2001). Characterisation of aluminium oxynitride gas barrier films. Thin Solid Films, Vol. 388, No. 1-2, (June 2001), pp. 78-86, ISSN 0040-6090

Xiao, W.; Jiang X. (2004). Optical and mechanical properties of nanocrystalline aluminum oxynitride films prepared by electron cyclotron resonance plasma enhanced chemical vapor deposition. Journal of Crystal Growth, Vol. 263, No. 1-3, (March 2004), pp. 165-171, ISSN 0022-0248

Uchida, H.; Yamashita, M.; Hanaki, S.; Fujimoto, T. (2006). Structural and chemical characteristics of $(\mathrm{Ti}, \mathrm{Al}) \mathrm{N}$ films prepared by ion mixing and vapor deposition. Vacuum, Vol. 80, No. 11-12, (September 2006), pp. 1356-1361, ISSN 0042-207X

Sato, A.; Azumada, K.; Atsumori, T.; Hara, K. (2007). Characterization of AlN:Mn thin film phosphors prepared by metalorganic chemical vapor deposition. Journal of Crystal Growth, Vol. 298, (January 2007), pp. 379-382, ISSN 0022-0248

Takahashi, N.; Matsumoto, Y.; Nakamura, T. (2006). Investigations of structure and morphology of the AIN nano-pillar crystal films prepared by halide chemical vapor deposition under atmospheric pressure. Journal of Physical and Chemistry of Solids, Vol. 67, No. 4, (April 2006), pp. 665-668, ISSN 0022-3697

Brown, P.D.; Fay, M.; Bock, N., Marlafeka, M.; Cheng, T.S.; Novikov, S.V.; Davis, C.S.; Campion, R.P., Foxon, C.T. (2002). Structural characterisation of Al grown on group III-nitride layers and sapphire by molecular beam epitaxy. Journal of Crystal Growth, Vol. 234, No. 2-3, (January 2002), pp. 384-390, ISSN 0022-0248

Iwata, S.; Nanjo, Y.; Okuno, T.; Kurai, S.; Taguchi, T. (2007). Growth and optical properties of AlN homoepitaxial layers grown by ammonia-source molecular beam epitaxy. Journal of Crystal Growth, Vol. 301-302, (April 2007), pp. 461-464, ISSN 0022-0248 
Lal, K.; Meikap, A.K. ; Chattopadhyay, S.K.; Chatterjee, S.K.; Ghosh, P.; Ghosh, M.; Baba, K.; Hatada, R. (2003). Frequency dependent conductivity of aluminium nitride films prepared by ion beam-assisted deposition. Thin Solid Films, Vol. 434, No. 1-2, (June 2003), pp. 264-270, ISSN 0040-6090

Matsumoto, T.; Kiuchi, M. (2006). Zinc-blende aluminum nitride formation using lowenergy ion beam assisted deposition. Nuclear Instruments and Methods in Physics Research, Vol. 242, No. 1-2, (January 2006), pp. 424-426, ISSN 0168-583X

Ohring, M. (2002). Materials Science of Thin Films: Deposition and Structure, London Academic Press. ISBN 0-12-524975-6

Powder Diffraction File, JCPDS International Centre for Diffraction Data, PA, 1998 (www.icdd.com)

Brien, V.; Pigeat, P. (2007). Microstructures diagram of magnetron sputtered AlN deposits: Amorphous and nanostructured films. Journal of Crystal Growth, Vol. 299, No. 1, (February 2007), pp. 189-194, ISSN 0022-0248

Callister Jr, W.D. (2006). Materials Science \& Engineering: an introduction. $6^{\text {th }}$ edition (2006) Wiley \& Sons. New York. ISBN 0471135763

Patterson, A.L. (1939). The Scherrer Formula for X-Ray Particle Size Determination. Physical Review, Vol. 56, No. 1, (July 1939), pp. 978-982, ISSN 1098-0121

Guo, Q.X.; Tanaka, T.; Nishio, M.; Ogawa, H. (2006). Growth properties of AlN films on sapphire substrates by reactive sputtering. Vacuum, Vol. 80, No. 7, (May 2006), pp. 716-718. ISSN 0042-207X

Swanepoel, R. (1983). Determination of the thickness and optical constants of amorphous silicon. Journal of Physics E: Scientific Instruments, Vol. 16, No. 12, (May 1983), pp. 1214-1222. ISSN 0022-3735

Zong, F.; Ma, H.; Du, W.; Ma, J.; Zhang, X.; Xiao, H.; Ji, F.; Xue, Ch. (2006). Optical band gap of zinc nitride films prepared on quartz substrates from a zinc nitride target by reactive rf magnetron sputtering. Applied Surface Science, Vol. 252, No. 22, (September 2006), pp. 7983-7986.ISSN 0169-4332

Guerra, J.A.; Montañez, L.; Erlenbach, O.; Galvez, G.; de Zela, F.; Winnacker, A.; Weingärtner, R. (2011). Determination of optical band gap of thin amorphous SiC and AlN films produced by RF magnetron sputtering. Journal of Physics: Conference series, Vol. 274, (September 2010), pp. 012113-012118, ISSN 1742-6588

Moulder, J.F.; Sticke, W.F.; Sobol, P.E.; Bomben, K.D. (1992) “Handbook of X-ray Photoelectron Spectroscopy". 2nd edition. Perkin-Elmer, Physical Electronics Division. Eden Prairie. ISBN 0962702625

Stanca, I. (2004). Chemical structure of films grown by AlN laser ablation: an X-ray photoelectron spectroscopy stydy. Romanian Journal of Physics, Vol. 49, No. 9-10, (May 2004), pp. 807-816, ISSN 1221-146X

Sohal, R.; Torche, M.; Henkel, K.; Hoffmann, P.; Tallarida, M.; Schmeiber, D. (2006). Aloxynitrides as a buffer layer for Pr2O3/SiC interfaces. Materials Science in Semiconductor Processing, Vol. 9, No. 6, (December 2006), pp. 945-948, ISSN 13698001 
Wang, P.W.; Sui, S.; Wang, W.; Durrer, W. (1997). Aluminum nitride and alumina composite film fabricated by DC plasma processes. Thin Solid Films, Vol. 295, No. 1-2, (February 1997), pp. 142-146, ISSN 0040-6090

Gredelj, S.; Gerson, A.R.; Kumar, S.; Cavallaro, G.P. (2001). Characterization of aluminium surfaces with and without plasma nitriding by X-ray photoelectron spectroscopy. Applied Surface Science, Vol. 174, No. 3-4, (April 2001), pp. 240250, ISSN 0169-4332

Richthofen, A. von; Domnick, R. (1996). Metastable single-phase polycrystalline aluminium oxynitride films grown by MSIP: constitution and structure. Thin Solid Films, Vol. 283, No. 1-2, (September 1996), pp. 37-44, ISSN 0040-6090

Robinson, K.S.; Sherwood, P.M.A. (1984). X-Ray photoelectron spectroscopic studies of the surface of sputter ion plated films. Surface and Interface Analysis, Vol. 6, No. 6, (December 1984), pp. 261-266, ISSN: 0142-2421

Huttel, Y.; Bourdie, E.; Soukiassian, P.; Mangat, P.S.; Hurych, Z. (1993). Promoted oxidation of aluminum thin films using an alkali metal catalyst. Journal of Vacuum Science and Technol A, Vol. 11, No. 4, (July 1993), pp. 2186-2192, ISSN 0734-2101

Gutierrez, A.; Lopez, M.F.; Garcia-Alonso, C.; Escudero, M. In: I. Olefjord, L. Nyborg, D. Briggs, 7th European Conf. Applications on Surface \& Interface Analysis, Göteborg (1997) 1035-1038, John Wiley \& Sons, Canada. ISBN 0471978272

Zhang, J.X.; Cheng, H.; Chen, Y.Z.; Uddin, A.; Yuan, S.; Geng, S.J.; Zhang, S. (2005). Growth of AlN films on $\mathrm{Si}(100)$ and $\mathrm{Si}(111)$ substrates by reactive magnetron sputtering. Surface and Coatings Technology, Vol. 198, No. 1-3, (August 2005), pp. 68-73, ISSN 0257-8972

Whangbo M.H.; Hoffmann, R. (1978). The band structure of the tetracyanoplatinate chain. J. Am. Chem. Soc., Vol. 100, No. 19, (September 1978), pp. 6093-6098, ISSN 00027863

Hoffmann, R. (1963). An Extended Hückel Theory I Hydrocarbons. J. Chem. Phys., Vol. 39, No. 6, (September 1963), pp. 1397-1413, ISSN 0021-9606

Landrum, G. A. YAeHMOP package: http://overlap.chem.Cornell.edu:8080/yaehmop.html

Galván, D.H. (1998). Extended Hückel Calculations on Cubic Boron Nitride and Diamond. Journal of Materials Science Letters, Vol 17, No. 10 (May 2008), pp. 805-810, ISSN 1573-4811

Ferreira da Silva, A.; Souza Dantas, N.; de Almeida, J.S.; Ahuja, R.; Person C. (2005). Electronic and optical properties of würtzite and zinc-blende TIN and AIN. Journal of Crystal Growth, Vol. 281, No. 1, (July 2005), pp. 151-160, ISSN 00220248

Rezaei, B.; Asgari, A.; Kalafi, M. (2006). Electronic band structure pseudopotential calculation of wurtzite III-nitride materials. Physica B, Vol. 371, No. 1, (January 2006), pp. 107-111, ISSN 0921-4526

Persson, C.; Ahuja, R.; Ferreira da Silva, A.; Johansson, B. (2005). First-principle calculations of optical properties of wurtzite AIN and GaN. Journal of Crystal Growth, Vol. 231, No. 3, (October 2001), pp. 407-414, ISSN 0022-0248 
García-Méndez, M.; Morales-Rodríguez, S.; Galván, D.H.; Machorro, R. (2009). Characterization of AIN thin films fabricated by reactive DC sputtering: experimental measurements and Hückel calculations. International Journal of Modern Phisics B, Vol. 33, No. 9, (April 2009), pp. 2233-2251, ISSN: 0217-9792 


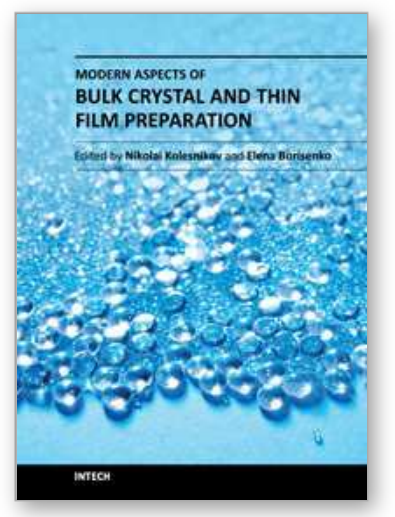

\author{
Modern Aspects of Bulk Crystal and Thin Film Preparation \\ Edited by Dr. Nikolai Kolesnikov
}

ISBN 978-953-307-610-2

Hard cover, 608 pages

Publisher InTech

Published online 13, January, 2012

Published in print edition January, 2012

In modern research and development, materials manufacturing crystal growth is known as a way to solve a wide range of technological tasks in the fabrication of materials with preset properties. This book allows a reader to gain insight into selected aspects of the field, including growth of bulk inorganic crystals, preparation of thin films, low-dimensional structures, crystallization of proteins, and other organic compounds.

\title{
How to reference
}

In order to correctly reference this scholarly work, feel free to copy and paste the following:

Manuel Garcia-Méndez (2012). Controlled Growth of C-Oriented AIN Thin Films: Experimental Deposition and Characterization, Modern Aspects of Bulk Crystal and Thin Film Preparation, Dr. Nikolai Kolesnikov (Ed.), ISBN: 978-953-307-610-2, InTech, Available from: http://www.intechopen.com/books/modern-aspects-of-bulkcrystal-and-thin-film-preparation/controlled-growth-of-c-oriented-aln-thin-films-experimental-deposition-andcharacterization

\section{INTECH}

open science | open minds

\author{
InTech Europe \\ University Campus STeP Ri \\ Slavka Krautzeka 83/A \\ 51000 Rijeka, Croatia \\ Phone: +385 (51) 770447 \\ Fax: +385 (51) 686166 \\ www.intechopen.com
}

\author{
InTech China \\ Unit 405, Office Block, Hotel Equatorial Shanghai \\ No.65, Yan An Road (West), Shanghai, 200040, China \\ 中国上海市延安西路65号上海国际贵都大饭店办公楼 405 单元 \\ Phone: +86-21-62489820 \\ Fax: $+86-21-62489821$
}


(C) 2012 The Author(s). Licensee IntechOpen. This is an open access article distributed under the terms of the Creative Commons Attribution 3.0 License, which permits unrestricted use, distribution, and reproduction in any medium, provided the original work is properly cited. 